\title{
MODELING MARKET RISK IN FRONTIER EQUITY MARKETS-EVIDENCE FROM SERBIA
}

\author{
Marko Milojević ${ }^{1}$, Ivica Terzić
}

\begin{abstract}
The need for understanding financial risk management and unique models for measuring risk in transitional capital markets increasingly gains in importance and becomes a very current issue. This article studies predictive ability of various classes of Value-at-Risk (VaR) models focusing on Serbian equity market in both stressed and normal market conditions. The five VaR models adopted in our evaluation procedure include: historical simulation with rolling window of 500 days, Risk Metrics, exponentially-weighted moving average (EWMA) with optimized decay factor, VaR based on models from GARCH family under three distributional assumptions (normal, generalized error, and Student-t), and Filtered historical simulation. In order to verify the forecasting performance of different VaR models, we employ a backtesting procedure, which consists of statistical tests. The results indicate that VaR based on conditional volatility models with asymmetric distribution of innovations behave reasonably well in both tranquil and crisis period. Standard VaR models developed for liquid and efficient markets seriously underestimate risk forecast in Serbian equity market under all circumstances.
\end{abstract}

JEL Classification Numbers: G17, G32, C53, DOI: http://dx.doi.org/10.12955/cbup.v2.455

Keywords: market risk, backtesting, forecasting, equity, EWMA, GARCH, VaR

\section{Introduction}

As KPMG (2008) pointed out: "The growing magnitude and complexity of trading accounts, coupled with increased market volatility over the last decade, have pushed financial institutions and regulators to adopt large-scale risk measurement models. Value-at-Risk $(\mathrm{VaR})$ is one of the most popular models of market risk analysis in the industry used both by institutions, for internal risk management, and by regulators to dictate regulatory market risk capital requirements. The model aggregates portfolio market risk exposures into one number-signifying the loss in a portfolio value. VaR is used to provide a number that states, with a certain level of confidence, the maximum loss that can occur in a defined time horizon - usually from one day up to a few months. The loss is calculated as the fall in market price of all or part of the portfolio."

The VaR model assumes that positions can be liquidated over a specified period. This liquidity assumption has proved invalid over the course of recent market events in both developed and emerging equity markets. The fact that the recent financial market crisis, originated in the American sub-prime mortgage market, had important implications on sudden drop in developed equity markets liquidity; the situation is more complex when we consider frontier stock markets, where stocks become practically illiquid. The accuracy of $\mathrm{VaR}$, when applied to relatively illiquid financial instruments and frontier equity markets, is subject to our empirical research. For VaR outputs to be reliable, we should have rigorous model validation and calibration processes. Those processes are a critical feature of financial risk management to ensure that $\mathrm{VaR}$ models are producing reliable and consistent VaR figures, on which we can make competent decisions. There are frontier equity markets, which have inherent valuation risk that could be material, which would not be picked up at the 95/99 percent VaR levels, highlighting the need to establish whether VaR is appropriate for particular asset classes in those markets (KPMG, 2008).

The equity market in Serbia is a frontier market. Frontier markets describe the smallest, less developed, less liquid countries that make up emerging markets. The main problem of the frontier markets impacting market liquidity are: small number of stocks with significant market capitalization, small numbers of outstanding shares, infrequent and irregular trading, etc. Additionally, there are

\footnotetext{
${ }^{1}$ Marko Milojević, Singidunum University, Republic of Serbia, mmilojevic@ singidunum.ac.rs

${ }^{2}$ Ivica Terzić, Singidunum University, Republic of Serbia, iterzic@singidunum.ac.rs
} 
typically short time series of past trades, lack of transparency and readily accessible information about traded companies, as well as the appearance of the so-called "invisible forms of risk," where illiquidity is the most important one. Due to all these factors, frontier markets suffer from the increased level of market risk (Minović, 2012).

$\mathrm{VaR}$ has become a popular risk measure and has been estimated by a number of methods, including variance-covariance, historical simulation, and Monte Carlo simulation methods (Beder, 1995; Hendricks, 1996; Mahoney, 1996; Alexander \& Leigh, 1997). Its popularity increased after the Bank for International Settlements and the Securities and Exchange Commission addressed VaR as a measure to quantify risk and the Basel Committee on Banking Supervision imposed VaR use on financial institutions. There are a number of papers on performance testing of various VaR models in developed and developing markets. In recent years, there has been a lot of research on VaR estimation of different return series (Giot \& Laurent, 2003; Sarma, Thomas, \& Shah, 2003; Huang \& Lin, 2004), but research papers dealing with VaR calculation in the financial markets of the new EU member states and EU candidates are very rare.

Similarly, Zikovic \& Aktan (2009) investigated the predictability of a wide array of VaR models with daily returns of Turkish and Croatian stock index. They concluded that only advanced and theoretically sound VaR models, such as EVT and HHS, can adequately measure equity risk in Turkish and Croatian equity markets in times of crisis.

Andjelić, Djaković, \& Radišić (2010) investigated the relative performance of VaR methods with the daily returns series in four different emerging markets of the selected Central and Eastern European countries. They found that those methods would produce accurate VaR estimates in developed markets, but do not necessarily have application in the emerging markets.

Đorić \& Đorić (2011) used a comparative study of the predictive ability of VaR estimates for BELEX15 index with various estimation techniques. Their findings should be interpreted with caution because they used short risk horizon data and only Kupiec's backtest, which is based on frequency of failures; therefore, the accuracy of VaR model should be evaluated by more sensitive test that measures the frequency, size, and is independent of losses.

Terzić \& Milojević (2013) evaluated performance of Value-at-Risk produced by two risk models in emerging and developed countries and concluded that during the crisis period, all tested VaR models underestimated the true level of market risk exposure.

Although there are studies that calculate the VaR by utilizing volatility modeling models, to the best of our knowledge, this is the unique study that compares the performance of VaR models in Serbian market economy by using data from the period that includes the recent global financial crisis. The performance of $\mathrm{VaR}$ is assessed using both the unconditional and conditional tests of Kupiec and Christoffersen, respectively.

The purpose of this article is to test and validate different VaR models in Serbian equity market. It is interesting how models for market risk assessment, created and most widely used in developed equity markets, estimate financial risks in frontier markets. Contribution of this article is that so far no-one has investigated relative performance of $\mathrm{VaR}$ and compared the financial data obtained by those models in the Serbian stock markets during an observed risk horizon. Another contribution is to extend the very scarce empirical research on VaR estimation in this financial market.

The rest of the article presents descriptions of tested VaR models and backtesting techniques, and provides description of the analyzed data and statistical characteristics of Serbian stock market. Findings and backtesting results are also presented and discussed, followed by a conclusion by summarizing the main results of the empirical research. 


\section{Methodology}

There are different approaches to VaR models for estimating the probable losses of a portfolio, which differ in calculating the density function of those losses.

We apply three types of VaR models in this study:

- the historical simulation, non-parametric model, which uses a large quantity of historical data to estimate $\mathrm{VaR}$, but makes minimal assumptions about the risk factor return distribution;

- parametric VaR based on GARCH and EWMA models;

- the filtered historical simulation, semi-parametric model, which computes VaR by combining historical simulation with GARCH estimates of volatility. Here, filtering refers to the use of estimated GARCH volatility to create standardized innovations from which we compute empirical quantile for VaR.

VaR is usually defined as the maximum potential loss that a portfolio can suffer within a fixed confidence level during a holding period (Alexander, 2008).

More technically, $\operatorname{VaR}(1-\alpha)$ is defined as the threshold that is exceeded $100 * \alpha$ times out of 100 trials on average. $1-\alpha$ is the confidence level where $\alpha \in(0,1)$ is a real number. The cases in which ex-post portfolio returns are lower than VaR estimates are called "violations." One main input to the VaR calculation is the confidence level, $(1-\alpha)$. Once the confidence level is set, VaR must be calculated in such a way that the violations should be equal to $100 * \alpha$. The second input that is necessary in order to calculate $\mathrm{VaR}$ is the standard deviation or volatility of the returns. Modeling and forecasting volatility is crucial for investors who are interested in the forecast of the variance of a time-varying portfolio return over the holding period.

The most recent and advanced VaR methods make use of GARCH models to calculate the conditional standard deviation (Köksal \& Orhan, 2013).

The VaR models, their formulations, and descriptions that we implied in the study are presented in Table 1.

\begin{tabular}{|c|c|c|}
\hline \multicolumn{2}{|l|}{ Table 1: VaR models used in the analysis } \\
\hline VaR Models & VaR Formulations & Description \\
\hline $\begin{array}{c}\text { Historical } \\
\text { simulation }\end{array}$ & $V a R^{c l}=F^{-1}(c l)=X_{t}$ & $F_{n}(t)=\frac{1}{n} \sum_{t=1}^{n} I\left(X_{t} \leq t\right)$ \\
\hline Risk Metrics & $V a R_{t}^{c l}=\mu_{t}+\sigma_{t} * \alpha_{c l}$ & $\sigma_{t}=\sqrt{0,94 \sigma_{t-1}^{2}+0,06 r_{t-1}^{2}}$ \\
\hline $\begin{array}{c}\text { GARCH VaR } \\
\text { Optimal EWMA } \\
\text { VaR }\end{array}$ & $V a R_{t}^{c l}=\mu_{t}+\sigma_{t} * \alpha_{c l}$ & $\sigma_{t}^{2}=\alpha_{0}+\alpha_{1} a_{t-1}^{2}+\beta_{1} \sigma_{t-1}^{2}$ \\
\hline
\end{tabular}




\begin{tabular}{|c|c|}
\hline \multirow[t]{2}{*}{$\begin{array}{l}\text { Filtered } \\
\text { Historical } \\
\text { simulation }\end{array}$} & $\begin{array}{c}\operatorname{VaR}_{t}^{p}=\sigma_{t} * \text { Percentile }\left\{\left\{\hat{z}_{t-\tau}\right\}_{\tau=1}^{m}, 100 p\right\} \\
\hat{z}_{t-\tau}=\frac{r_{t-\tau}}{\sigma_{t-\tau}}, \tau=1,2, \ldots \ldots, m\end{array}$ \\
\hline & $\sigma_{t}^{2}=\alpha_{0}+\alpha_{1} a_{t-1}^{2}+\beta_{1} \sigma_{t-1}^{2}, \quad \sigma_{t}=\sqrt{\sigma_{t}^{2}}$ \\
\hline
\end{tabular}

Source: Authors

In order to validate aforementioned $\mathrm{VaR}$ models we empoly two backtests: unconditional coverage and independent test.There are basically two approaches that use backtesting to compare the performance of VaR calculations in the finance literature. The unconditional approach does not take the sequence of violations into account. Using this approach, Kupiec (1995) defines the following test statistics, which follows the chi-square distribution with one degree of freedom:

$$
L R_{u c}^{k u p}=-2 \log \frac{L\left(p ; I_{1}, I_{2}, \ldots, I_{n}\right)}{L\left(\widetilde{p} ; I_{1}, I_{2}, \ldots, I_{n}\right)} \sim \chi^{2}
$$

The imperfection of the Kupiec test is that it does not take into account the sequence of violations. To improve upon this shortcoming, Christoffersen (1998) designed a test that emphasizes the predecessor of a violation. As stated by Christoffersen (1998), testing solely for correct unconditional coverage of a VaR model neglects the possibility that violations might cluster over time. Consequently, Christoffersen (1998) proposed a test of the violations that is independent from an explicit first-order Markov alternative. The resulting test model is given by Equation (2),

$$
L R_{\text {iid }}^{\operatorname{mar}}=-2 \log \frac{L\left(\widetilde{\left.\Pi_{2} ; I_{1}, I_{2}, \ldots, I_{n}\right)}\right.}{L\left(\widetilde{\left.\Pi_{1} ; I_{1}, I_{2}, \ldots, I_{n}\right)}\right.} \sim \chi^{2}
$$

\section{Data and Empirical Analysis}

Daily historical data on the Serbian blue chip stock index (BELEX 15) from October $4^{\text {th }}, 2005$ until December 31 ${ }^{\text {st }}, 2013$ are downloaded from Belgrade Stock Exchange. Using the same data set for each, we applied the five models to estimate the 1-day VaR at 95\% and 99\% confidence level. Thus, we used data from both before and after the 2008 financial crisis. This series of price is converted to returns series. For a series of prices $\mathrm{P}_{t}$, the return $\mathrm{r}_{t}$ is obtained using:

$$
r_{t}=\ln \frac{P_{t}}{P_{t-1}}
$$

Data sets for VaR estimation started 500 days later and covered the period from January $1^{\text {st }}, 2007$ until December $31^{\text {st }}, 2013$ in order to initialize the estimation. The rest of the observation we used for backtesting purposes. Through a simulation methodology, we attempted to determine how each VaR approach would have performed over a realistic range of index over the sample period. We investigated out-of-sample (forecasting) performance based on the unconditional coverage test and Christoffersen independent test. Backtesting diagnostics of $1577 \mathrm{VaR}$ forecasts for analyzed stock index are presented in Table 6. Before analyzing predictive performance of VaR models, some stylized facts of return series were tested and presented in Tables 2 through 5.

\begin{tabular}{|l|c|r|}
\hline Table 2: Descriptive statistics of the Belex 15 return series \\
\hline \multirow{3}{*}{ Descriptive Statistics } \\
\cline { 2 - 3 } & AVERAGE: & $-0.03 \%$ \\
\cline { 2 - 3 } & STD DEV: & $1.46 \%$ \\
\cline { 2 - 3 } & SKEW: & 0.15 \\
\hline
\end{tabular}




\begin{tabular}{|l|r|r|}
\hline \multirow{5}{*}{} & $\begin{array}{c}\text { EXCESS- } \\
\text { KURTOSIS: }\end{array}$ & 12.24 \\
\cline { 2 - 3 } & MEDIAN: & $-0.02 \%$ \\
\cline { 2 - 3 } & MIN: & $-10.86 \%$ \\
\cline { 2 - 3 } & MAX: & $12.16 \%$ \\
\cline { 2 - 3 } & Q 1: & $-0.62 \%$ \\
\hline Source: Authors & $\mathbf{Q ~ 3 :}$ & $0.56 \%$ \\
\hline
\end{tabular}

Table 2 shows the descriptive statistics of the index daily returns. The average return is close to zero. The unconditional standard deviations is $1.46 \%$. Belex 15 exhibits kurtosis above 3 . Another feature of the return series is the presence of skewness. In fact, the index is positively skewed. The quartiles shown in the table $(\mathrm{Q} 1, \mathrm{Q} 3)$ inscribe $50 \%$ of the values in the sample. The inter-quartile range (IQR) can be used to characterize the data when there may be extremities that skew the data. The interquartile range is a relatively robust statistic (also sometimes called "resistant") compared to the range and standard deviation. These indicate that the return series is non-normal. We confirmed this nonnormality via the Jarque-Bera, Shapiro-Wilk, and Doornick Chi-Square tests performed at the 5\% level, as presented in Table 3. The results obtained by test statistics lead to the rejection of the null hypothesis of normality.

\begin{tabular}{|c|c|c|c|c|c|}
\hline & Normality Test & Score & C.V. & P-Value & Pass? \\
\hline & Jarque-Bera & 12904.63 & 5.99 & $0.0 \%$ & FALSE \\
\hline & Shapiro-Wilk & 0.86 & \#N/A & $0.0 \%$ & FALSE \\
\hline & Doornick Chi-Square & 2682.61 & 5.99 & $0.0 \%$ & FALSE \\
\hline
\end{tabular}

\begin{tabular}{|l|c|c|r|r|r|}
\hline Table 4: ARCH effect test of BELEX 15 \\
\hline & \multicolumn{5}{|c|}{ ARCH Effect Test } \\
\cline { 2 - 6 } & Lag & \multicolumn{1}{|c|}{ Score } & \multicolumn{1}{|c|}{ C.V. } & P-Value & Present? \\
\cline { 2 - 6 } & $\mathbf{1}$ & 246.17 & 3.84 & $0.0 \%$ & TRUE \\
\cline { 2 - 6 } & $\mathbf{5}$ & 568.96 & 11.07 & $0.0 \%$ & TRUE \\
\cline { 2 - 6 } & $\mathbf{1 0}$ & 745.67 & 18.31 & $0.0 \%$ & TRUE \\
\cline { 2 - 6 } & $\mathbf{1 5}$ & 848.83 & 25.00 & $0.0 \%$ & TRUE \\
\cline { 2 - 6 } & $\mathbf{2 0}$ & 899.00 & 31.41 & $0.0 \%$ & TRUE \\
\cline { 2 - 6 } & $\mathbf{2 5}$ & 916.82 & 37.65 & $0.0 \%$ & TRUE \\
\hline Source: Authors & & & &
\end{tabular}

Engle's ARCH test (see Table 4) performed at the 5\% level with up to 25 lags concludes that ARCH effects is present in the data, and motivates the use of GARCH models for volatility forecasting.

Finally, Table 5 shows the Ljung-Box Q test statistics (white noise test) for auto-correlation in returns. The test performed at the 5\% significance level and with up to 25 lags concludes that auto-correlation is present in return series considered. The above features motivate the need for heteroskedasticity models for calculating VaR. 
CBU INTERNATIONAL CONFERENCE ON INNOVATION, TECHNOLOGY TRANSFER AND EDUCATION

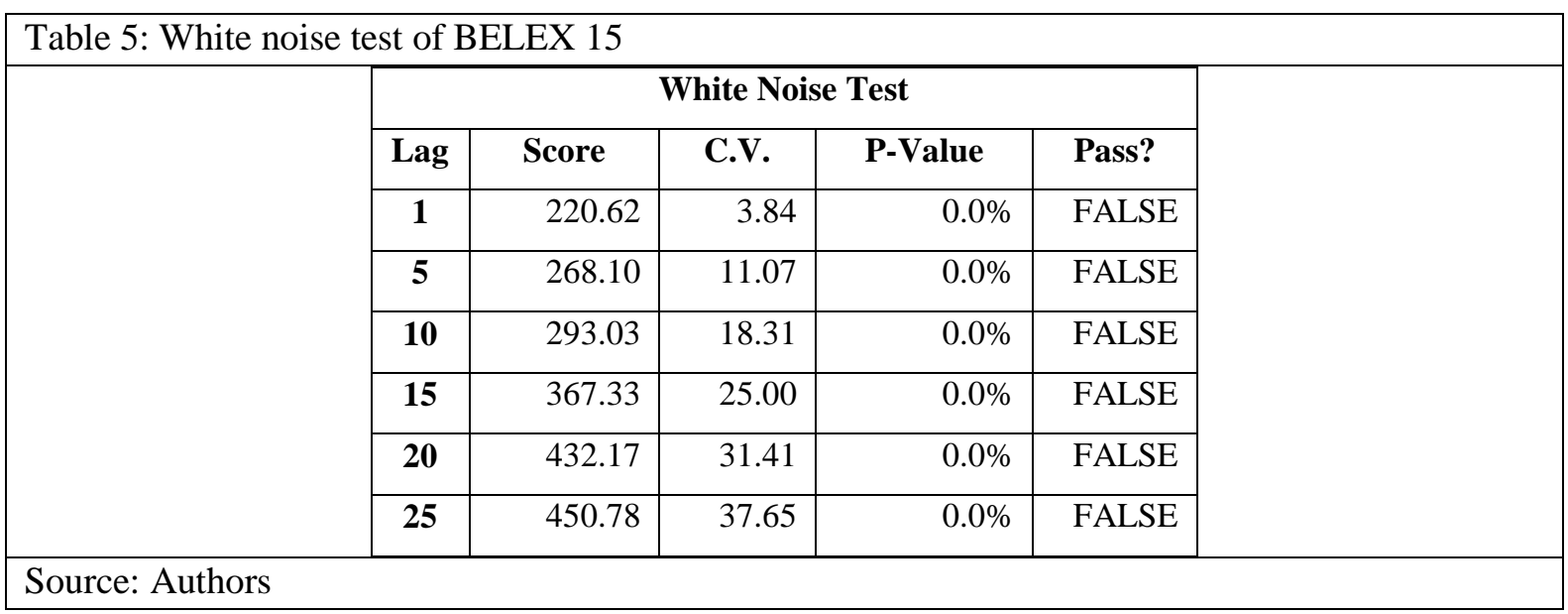

The backtesting results of VaR models for the Belex 15 are shown in Table 6. We considered the results of the statistical tests for unconditional coverage and independence property.

\begin{tabular}{|c|c|c|c|c|c|c|c|c|c|c|}
\hline & \multicolumn{10}{|c|}{ BELEX 15} \\
\hline & \multicolumn{2}{|c|}{ HS } & \multicolumn{2}{|c|}{$\mathbf{R M}$} & \multicolumn{2}{|c|}{ EWMA optimal } & \multicolumn{2}{|c|}{ GARCH t-student } & \multicolumn{2}{|c|}{ FHS with GARCH } \\
\hline & $1 \%$ & $5 \%$ & $1 \%$ & $5 \%$ & $1 \%$ & $5 \%$ & $1 \%$ & $5 \%$ & $1 \%$ & $5 \%$ \\
\hline $\mathbf{T}_{0}$ & 1554 & 1504 & 1550 & 1500 & 1542 & 1478 & 1550 & 1499 & 1562 & 1511 \\
\hline $\mathrm{T}_{1}$ & 23 & 73 & 27 & 77 & 35 & 99 & 27 & 78 & 15 & 66 \\
\hline $\mathbf{T}_{00}$ & 1538 & 1455 & 1529 & 1438 & 1509 & 1396 & 1524 & 1432 & 1536 & 1442 \\
\hline $\mathbf{T}_{01}$ & 14 & 42 & 21 & 62 & 33 & 82 & 26 & 67 & 20 & 63 \\
\hline$T_{10}$ & 16 & 49 & 21 & 62 & 33 & 82 & 26 & 67 & 21 & 64 \\
\hline $\mathbf{T}_{11}$ & 7 & 24 & 6 & 15 & 2 & 17 & 1 & 11 & 0 & 8 \\
\hline$\hat{\mathbf{p}}$ & $1,46 \%$ & $4,63 \%$ & $1,71 \%$ & $4,88 \%$ & $2,22 \%$ & $6,28 \%$ & $1,71 \%$ & $4,95 \%$ & $0,95 \%$ & $4,19 \%$ \\
\hline $\mathbf{L}(\hat{\mathbf{p}})$ & $7,15 \mathrm{E}-53$ & $4,20 \mathrm{E}-129$ & 4,79E-60 & $2,61 \mathrm{E}-134$ & $1,22 \mathrm{E}-73$ & $2,32 \mathrm{E}-161$ & 4,79E-60 & $1,35 \mathrm{E}-135$ & $3,62 \mathrm{E}-30$ & 2,35E-109 \\
\hline $\mathbf{L}(\mathbf{p})$ & $1,65 \mathrm{E}-53$ & $3,32 \mathrm{E}-129$ & $1,72 \mathrm{E}-61$ & $2,55 \mathrm{E}-134$ & $1,86 \mathrm{E}-77$ & $1,88 \mathrm{E}-162$ & $1,72 \mathrm{E}-61$ & $1,34 \mathrm{E}-135$ & $3,57 \mathrm{E}-30$ & 2,35E-109 \\
\hline$\hat{\mathbf{p}}_{01}$ & $0,90 \%$ & $2,79 \%$ & $1,35 \%$ & $4,13 \%$ & $2,14 \%$ & $5,55 \%$ & $1,68 \%$ & $4,47 \%$ & $0,98 \%$ & $4,59 \%$ \\
\hline$\hat{\mathbf{p}}_{11}$ & $30,43 \%$ & $32,88 \%$ & $22,22 \%$ & $19,48 \%$ & $5,71 \%$ & $17,17 \%$ & $3,70 \%$ & $14,10 \%$ & $0,00 \%$ & $12,70 \%$ \\
\hline $\mathbf{L}\left(\hat{\mathbf{p}}_{\mathbf{1}}\right)$ & $1,52 \mathrm{E}-41$ & $5,71 \mathrm{E}-104$ & $3,16 \mathrm{E}-55$ & $2,28 \mathrm{E}-129$ & $2,50 \mathrm{E}-73$ & $4,97 \mathrm{E}-158$ & $6,12 \mathrm{E}-60$ & $2,24 \mathrm{E}-133$ & $4,11 \mathrm{E}-30$ & $4,40 \mathrm{E}-108$ \\
\hline $\mathbf{L R}_{\mathrm{uc}}$ & 2,9332352 & 0,4679841 & 6,6582554 & 0,0460322 & 17,584545 & 5,0316015 & 1,3991006 & 0,0096782 & 0,0293246 & 0 \\
\hline $\mathbf{L R}_{\text {ind }}$ & 52,169745 & 115,74755 & 22,196164 & 22,760814 & 1,4259982 & 15,336746 & 1,476029 & 10,22473 & 0,2501044 & 3,8639388 \\
\hline \multicolumn{11}{|c|}{ Hypothesis testing (Chi square Test with 5\% significiant) } \\
\hline $\mathbf{L R}_{\mathrm{uc}}$ & Accept & Accept & Reject & Accept & Reject & Reject & Accept & Accept & Accept & Accept \\
\hline $\mathbf{L R}_{\text {ind }}$ & Reject & Reject & Reject & Reject & Accept & Reject & Accept & Reject & Accept & Accept \\
\hline
\end{tabular}

Source: Authors

As can be seen in Table 5, satisfactory performance with regards to Kupiec (unconditional coverage) and Christoffersen independence criteria is recorded for parametric model (GARCH VaR) and semiparametric model (FHS VaR) at both confidence levels. Very weak performance is recorded for HS, RM and EWMA optimal VaR. The results of backtests for HS and RM VaR in Serbian stock market are consistent with earlier findings of Terzić \& Milojević (2013), which leads us to conclude that HS and RM VaR models are not sutible for measuring market risk in this financial market. Thus, the failure of these models is confirmed for various time series data.

As criteria for validation of VaR models, we chose results of two tests and based our findings on the fact that VaR models must simultaneously satisfy both unconditional coverage and independence property. According to that, in the case of the first three VaR models, neither one fully satisfied both criteria of backtesting VaR models. We can conclude that HS, RM, and optimal EWMA 1\% and 5\% VaR significantly underestimate the true level of market risk in observed window length. 
On the other hand, the use of more sophisticated models based on GARCH volatility forecasting, especially combination of historical simulation with GARCH estimates of volatility (FHS), significantly improves the market risk assessment and quantifies risk accurately.

\section{Conclusion}

This article presents a Value-at-Risk analysis of the Serbian stock market by conducting an investigation using Belex 15 blue chip index daily log-returns sample data. A wide variety of VaR models has been presented and empirically evaluated by applying them to Serbian stock market index. Conducted preliminary statistical tests indicated that volatility clustering and occurrence of extreme negative returns characterize the returns of stock index. From statistical analysis of stock index performed in this study, it was determined that returns on Serbian equity index are characterized by fat tail and asymmetry. In other words, extreme movements are more probable than those predicted by normal-distribution model. The log returns exhibit significant serial correlation and ARCH effect. These characteristics of analyzed stock index have serious consequences on the performance of well known VaR models, such as historical simulation and RiskMetrics. These findings are documented in our backtesting procedure.

Furthermore, we have also developed EWMA VaR with optimized decay factor for the Serbian stock market, which in regard to RiskMetrics passed independence property, but the number of violations were not in accordance with confidence levels (unconditional coverage). The analysis of two other VaR models was based on the fitting of GARCH model to financial return series. The estimation of the parameters in the model was examined with three distributional assumptions for the innovations: Gaussian distribution, Student-t distribution, and GED distribution. The GARCH(1,1) with Student-t distribution innovations seem like a reasonable model for the Serbian index daily-log returns; it has the highest log-likelihood value and the model assumptions are largely satistifed. After specification of GARCH, we used VaR model to convert GARCH figures to the maximum possible loss amount. The results indicated that GARCH $(1,1)$ model with Student-t distribution is suitable for modelling Serbian stock index return series, hence, the VaR captures stocks' price movements very well.

The GARCH(1,1) conditional volatilitiy moves together with EWMA, but it is consistently lower and, in many cases, responds faster than EWMA. Thus, that is one more reason why VaR, based on GARCH conditional volatility, exhibits superiority compared to VaR based on models from EWMA family. Finally, we could see that during the observed period, FHS as a risk measurement model works more accurately than GARCH VaR. Our testing suggested that filtered historical simulation, with daily asymmetric GARCH specification, is most capable of modelling market risk accurately for the Serbian equity market at both tested confidence levels.

\section{Reference}

Alexander, C. (2008). Value at Risk Models. Chichester: John Wiley \& Sons.

Alexander, C., \& Leigh, C. (1997). On the covariance matrices used in value at risk models. The Journal of Derivatives, 4 , 50-62.

Andjelić, G., Djaković, V., \& Radišić, S. (2010). Application of VaR in emerging markets: A case of selected Central and Eastern European Countries. African Journal of Business Management, 4(17), 3666-3680.

Beder, T. (1995). VAR: Seductive but dangerous. Financial Analysts Journal, 12-24.

Christoffersen, P. (1998). Evaluating Interval Forecasts . International Economic Review, 39(4), 841-862.

Đorić, E., \& Đorić, D. (2011). Dynamic Value at Risk Estimation for BELEX15. Metodoloski zvezki, 8(1), 79-98.

Gencay R, \& Selcuk, F. (2004). Extreme value theory and Value-at-Risk: Relative performance in emerging markets. International Journal of Forecasting, 20(2), 287-303. 
Giot, P., \& Laurent, S. (2003). Value-at-Risk for long and short trading positions. Journal of Applied Econometrics, 18, 641664.

Halbleib, R., \& Pohlmeier, W. (2012). Improving the value at risk forecasts: Theory and evidence from the financial crisis. Journal of Economic Dynamics and Control, 36, 1212-1228.

Hendricks, D. (1996). Evaluation of value-at-risk models using historical data. Federal Reserve Bank of New York Economic Policy Review, 39-69.

Huang, Y., \& Lin, B. (2004). Value-at-Risk analysis for Taiwan stock index futures: Fat tails and conditional asymmetries in return innovations. Review of Quantitative Finance and Accounting, 22, 79-95.

Köksal, B., \& Orhan, M. (2013). Market Risk of Developed and Emerging Countries During the Global Financial Crisis . Emerging Markets Finance and Trade , 49(3), 20-34.

Kupiec, P. H. (1995). Techniques for verifying the accuracy of risk measurement models. Journal of Derivatives, 2, $73-84$.

Lopez, A. (1998). Methods for evaluating value-at-risk estimates. Federal Reserve Bank of NewYork. Economic Policy Review, 4(3), 3-17.

Mabrouka, S., \& Saadib, S. (2012). Parametric Value-at-Risk analysis: Evidence from stock indices. The Quarterly Review of Economics and Finance, 52(3), 305-321.

Mahoney, J. (1997). Forecast biases in value-at-risk estimations: Evidence from foreign exchange and global equity portfolios. LSE Financial Markets, Special Paper Series, no. 93.

Minović, Z. (2012). Liquidity of the Croatian stock market: an empirical analysis. Ekonomska istraživanja, 776-802.

Orhan, M., \& Akin, A. (2011). Performance of VaR in Assessing Risk: Evidence from the Istanbul Stock Exchange. Joumal of Economic and Social Research, 13(1), 57-73.

Sarma, M., Thomas, S., \& Shah, A. (2003). Selection of VaR models. Journal of Forecasting, 22, 337-358.

Terzić, I., \& Milojević, M. (2013). Evaluating Measures of Market Risk in Circumstances of Global Financial CrisisEmpirical Evidence from Five Countries. CBU International Conference Proceedings, 75-86. Prague: Central Bohemia University.

Živkovic, S. (2007). Testing popular VaR models in EU new member and candidate states. The Proceedings of Rijeka Faculty of Economics, 25, 325-346.

Živkovic, S., \& Aktan, B. (2009). Global financial crisis and VaR performance in emerging markets: A case of EU candidate states Turkey and Croatia. Proceedings of Rijeka Faculty of Economics, 27(1), 149-170. 